\title{
Erratum to: Molecular characterization of the translocation breakpoints in the Down syndrome mouse model Ts65Dn
}

\author{
Laura G. Reinholdt • Yueming Ding • Griffith J. Gilbert • \\ Anne Czechanski · Jeffrey P. Solzak · Randall J. Roper • \\ Mark T. Johnson • Leah Rae Donahue - Cathleen Lutz • \\ Muriel T. Davisson
}

Published online: 1 November 2011

(C) Springer Science+Business Media, LLC 2011

\section{Erratum to: Mamm Genome}

\section{DOI 10.1007/s00335-011-9357-z}

In the above-mentioned article, published in this issue of Mammalian Genome, the corrected authors names are listed above. Citation of this article should read Reinholdt LG, Ding Y, Gilbert GJ, et al. (2011) and not Reinholdt LG, Ding Y, Gilbert GT, et al. (2011).

The online version of the original article can be found under doi:10.1007/s00335-011-9357-z.

L. G. Reinholdt $(\bowtie) \cdot$ G. J. Gilbert · A. Czechanski ·

L. R. Donahue · C. Lutz - M. T. Davisson

The Jackson Laboratory, Genetic Resource Science,

600 Main St., Bar Harbor, ME 04609, USA

e-mail: laura.reinholdt@jax.org

\section{Y. Ding}

Regeneron Pharmaceuticals Inc., 777 Old Saw Mill River Road,

Tarrytown, NY 10591, USA

J. P. Solzak · R. J. Roper

Department of Biology, Indiana University-Purdue University

Indianapolis, 723 W. Michigan Street, SL 306,

Indianapolis, IN 46202, USA

\section{T. Johnson}

Department of Obstetrics and Gynecology,

University of Michigan Medical School,

1301 Catherine St., Arbor, MI 48109, USA 